\section{HARWELL: THE BRITISH ATOMIC ENERGY RESEARCH ESTABLISHMENT}

Prepared under the direction of Sir John Cockcroft, Director, Harwell Philosophical Library, N. Y. $\quad \$ 3.75$

Reviewed by John G. Teasdale Research Fellow in Physics

This Report on the atomic energy research in the United Kingdom is a description of the progress of a scientific endeavor, rather than that of the development of a military weapon. It lacks, then, the vividly recounted military-scientific decisions characteristic of the Smyth Report. The general advances in the field of atomic energy are amply illustrated in the remarkable progress of the Harwell establishment. The magnitude of the administrative as well as the technological problems in setting up such an establishment is made clear to the reader. The social and political implications are left to his imagination.

The book contains an account of the establishing of Harwell in 194,6 and of the subsequent progress. The major fields of research and technology undertaken at Harwell are described in detail, together with an indication of those related fields of technology which seem best handled by private industry rather than by a laboratory of fundamental research. The progress of reactor design and construction at Harwell is reported, together with the results and the future plans for fundamental research. The program of particle acceleration and associated research is also reported. The production and use of isotopes (radioactive and stable) are briefly discussed.

In addition to the programs of fundamental research, the associated technological problems which arise in such fields as chemistry, metallurgy, and medicine are described. Such typical problems as health protection for employees and disposal of waste products are also treated.

The reader will also find here an excellent description of the theory and design of such tools of research as the nuclear reactor, impulse accelerator, van de Graaff generator, cyclotron, betatron, synchrotron, and linear accelerator. In a general manner, many of the detection and monitoring tools of nuclear physics are described as well.

The book is, then, more than a history of an administrative effort; it is a progress report describing techniques and results. It succeeds in bringing to its reader an appreciation of the magnitude and ramifications of non-military atomic research by recounting the success at Harwell.

\section{MESONS-A SUMMARY OF EXPERIMENTAL FACTS \\ by Alan M. Thorndike \\ McGraw-Hill, New York}

Reviewed by Robert F. Christy Professor of Theoretical Physics

The careful reader of this book will indeed find a reasonably complete summary of experimental information available on mesons. It is complete in the sense that most of the relevant work is mentioned andreferred to and some of the more

CONTINUED ON PAGE 6

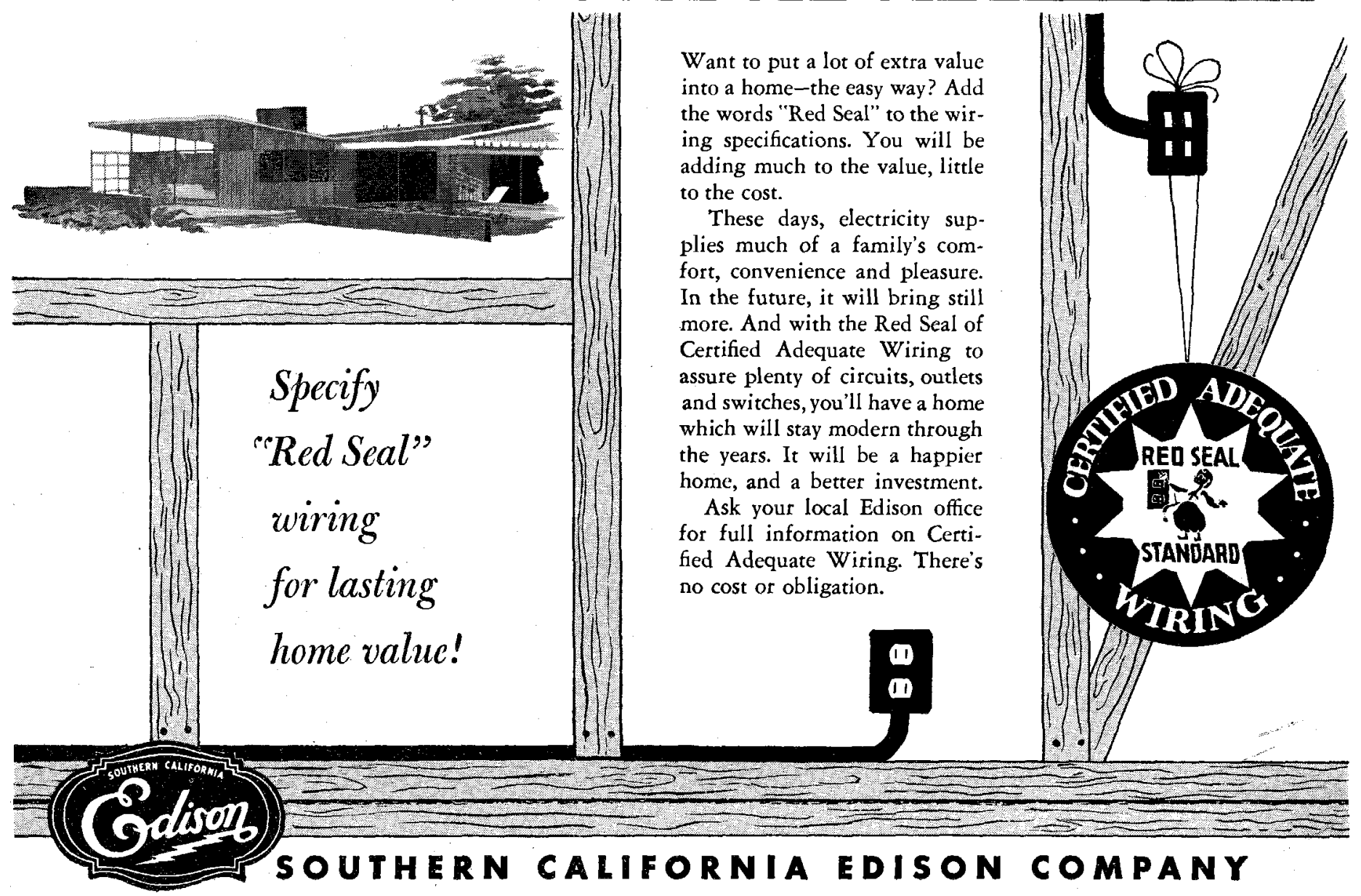


mesons, gives the mass of the $\mathrm{pi}$ meson, and describes the discovery of the pi-zero meson.

In Chapter 5 are collected data easily digested results are briefly quoted. It does not attempt a detailed discussion of very many items in the imposing list of references.

The diversity of the experimental material on mesons demands some guiding principle in the organization of the book. The author has chosen an essentially logical or didactic type of organization. Thus Chapter 1 provides the original evidence for the existence of mesons in cosmic rays and Yukawa's. ideas on nuclear forces. Chapter 2 reviews the data on the properties of the cosmic-ray (mu) mesons such as mass, charge and spin. Chapter 3 discusses new types of mesons, pi and others. The discussion of the heavier particles is of course already out of date.

As far as the pi meson is concerned, only a small part of the findings (mass by grain counting) of the basic experiment in its discovery is given in Chapter 3 since the other findings can be logically included in later chapters. Chapter 4 discusses some of the fundamental experiments on artificial production of ticularly as a guide to the literaturt.

The organization of the material has, however, also brought with it some very serious disadvantages. The fact that the original and striking experiments on pi-mu decay, for example, are dissected into three parts in as many, chapters, prevents any appreciation or understanding of the work and leaves only a dry collection of apparently unrelated facts, devoid of interest to the reader. $\mathrm{Nu}$ clear capture of mu mesons has received similar treatment with the same result: what was an exciting and important discovery is presented, not only without interest, but also in such a way that an understanding of the interrelation of various types of experimental results is apt to be missed.

The book also suffers from the almost total lack of theoretical discussion and argument. Even although no complete or adequate theory of mesons exists, there are many points - such as meson spin and the selection rules in meson capture in hydrogen-where a little theory is very illuminating and can very materially help to tie together what is otherwise, as it is in this book, an undigested collection of facts.

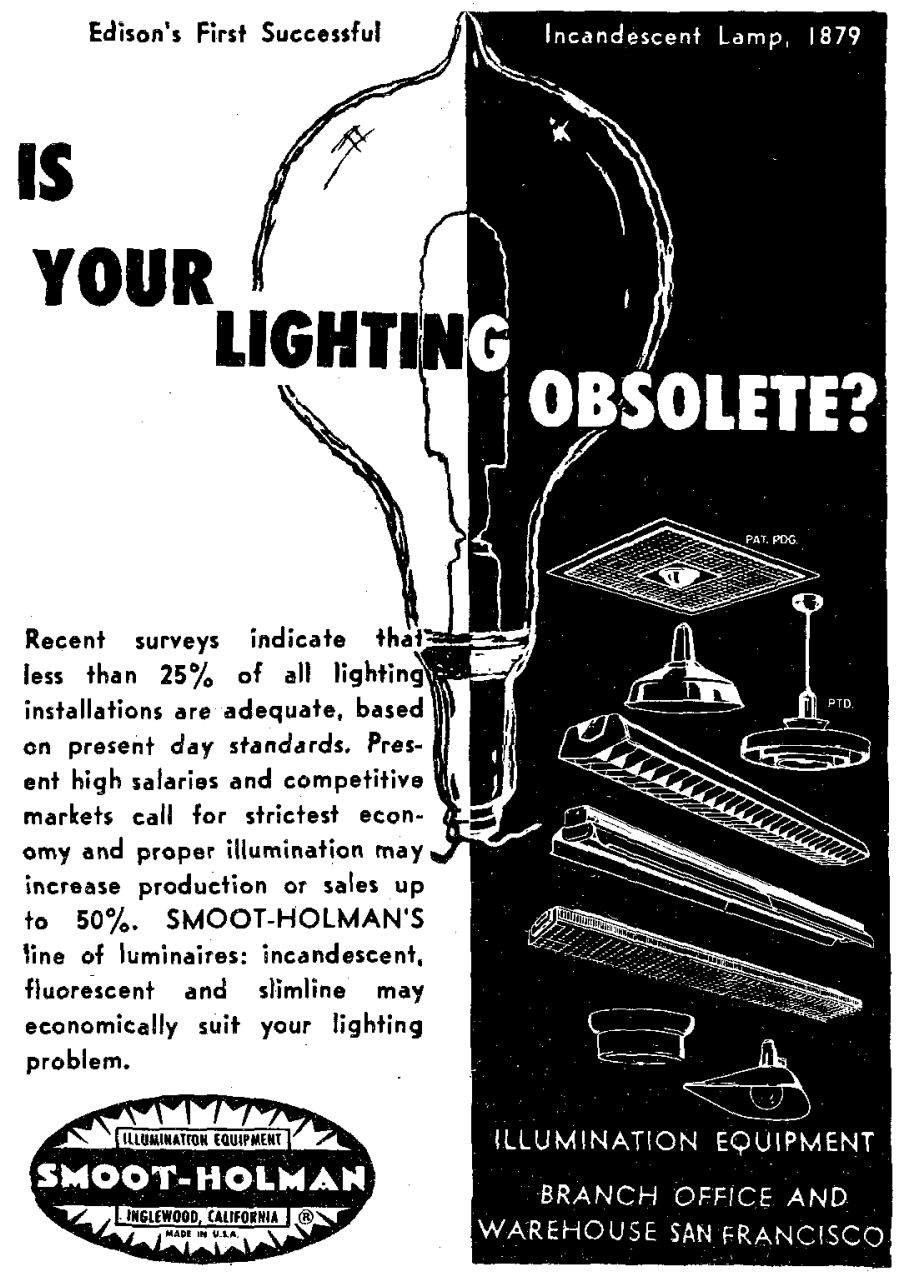

\section{SIT HACK AN D RELAX}

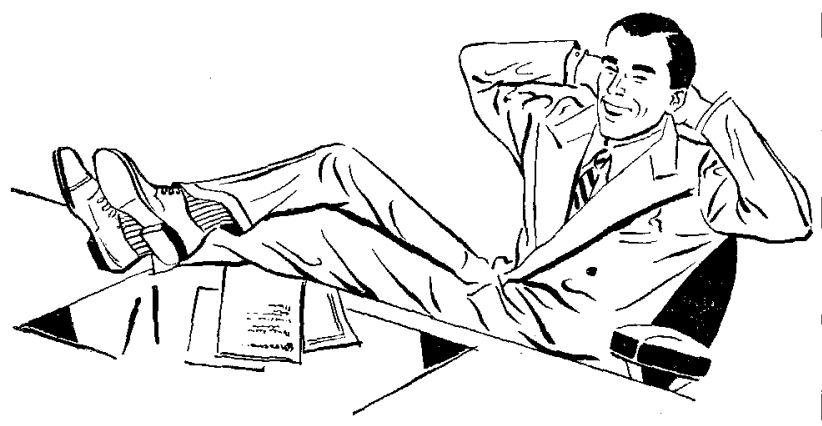

\section{Let Calmec Manufacturing Company Worry About Your Metal Parts and Products}

We have the most modern facilities and most complete plant to give you the maximum of service, whether it is a small part, a large part, or a product from your ideas to the shipped article direct to your customers, under your name, from our plant.

\section{CALMEC MANUFACTURING Co.}

Robert A. McIntyre, M.S. '38 KImball 6204 5825 District Blvd. Los Angeles 22, Calif. 